\title{
Influence of exercise on cognitive processing of older women during dual-task balance: sixteen case reports
}

\author{
ANA C. M. A. RODRIGUES $1,2,3 \mid$ RODOLPHO C. R. TININI ${ }^{4}$ | VALESKA GATICA-ROJAS ${ }^{\mid}$ALFREDO M. B. DE PAULA ${ }^{1}$ \\ ANDRE L. S. GUIMARÃES ${ }^{1}$ | RENATO S. MONTEIRO-JUNIOR ${ }^{1,3,6}$
}

1Postgraduate Program of Health Sciences (PPGCS), State University of Montes Claros, Montes Claros/MG, Brazil.

2Physiotherapy, Faculty Santo Agostinho, Montes Claros/MG, Brazil.

3Postgraduate Program of Neurology (PPGN), Fluminense Federal University, Niteroi/RJ, Brazil.

${ }_{4}^{4}$ Institute of Agricultural Sciences, Federal University of Minas Gerais, Av. Universitária 1000, Universitário, Montes Claros/MG, Brazil.

${ }_{5}^{5}$ uman Motor Control Laboratory, Department of Human Movement Sciences, Faculty of Health Sciences, Interdisciplinary Excellence Research Program on Healthy

Aging (PIEI-ES), Universidad de Talca, Av. Lircay S/N, Talca, Chile.

${ }^{6}$ Departament of Physical Education, State University of Montes Claros, Av. Doutor Ruy Braga s/n, Vila Mauricéia, Montes Claros/MG, Brazil.

Correspondence to: Ana Carolina de Mello Alves Rodrigues.Physiotherapy, Faculty Santo Agostinho, Montes Claros/MG, Brazil. Address: Avenida Osmane Barbosa, 937, Conj. Res. JK - Montes Claros-MG. Telephone: +55 38992327564.

email: acmarodrigues@gmail.com

https://doi.org/10.20338/bjmb.v14i01.160

\author{
HIGHLIGHTS \\ - Cognitive load impairs quiet postural balance \\ of older adults during a dual-task. \\ - There is high mediolateral oscillation of \\ postural control in a dual-task condition. \\ - Physical exercise in dual-task improves motor \\ and cognitive performance. \\ ABBREVIATIONS \\ ACSM American College of Sports \\ Medicine \\ ADLs activities of daily living \\ CE closed eyes \\ CoP Center of pressure \\ CoPap anteroposterior CoP displacement \\ $\mathrm{CoPml}$ mediolateral $\mathrm{CoP}$ displacement \\ DT dual-task \\ HRR heart rate reserve \\ MMSE Mini-Mental State Examination \\ OE open eyes \\ SPE subjective perceived exertion \\ WWB Wii Balance Board
}

BACKGROUND: Older adults require special attention during cognitive-motor tasks since automatic postural control is reduced.

AIM: To analyze the effect of physical exercise on dual-task processing of healthy older women performing standing balance.

METHOD: Sixteen healthy older women were assessed in a quiet standing position with eyes open/closed (singletask, EO, and EC) and with a cognitive task (dual-task, DT) using a Wii Balance Board. All individuals performed training (aerobic, strength, and virtual reality exercises) at moderate effort. Center of pressure (CoP) anteroposterior and mediolateral displacement were analyzed over time pre- and post-training. The Wilcoxon test was used to compare pre- and post-training.

RESULTS: Greater variability in CoP was observed pre- compared to post-training. In the DT, there was a significance decrease in post-training variability compared to pre-training $(p<0.01)$.

CONCLUSION: Physical exercise programs for older adults may contribute to simultaneously improving motorcognitive performances, associated with improvement in the divided attention.

KEYWORDS: Motor-cognitive task| Balance | Physical Performance | Older adults

PUBLICATION DATA

Received 31012020

Accepted 27032020

Published 01042020

\section{INTRODUCTION}

The aging process promotes changes in the brain and sensorimotor system, resulting in cognitive (e.g. deficits in executive functions and attentional resources) and postural balance declines ${ }^{1-3}$. Impairments in the integration of these systems influences performance in activities of daily living (ADLs) due to the relationship of cognitive domains and motor behavior. Older adults require more attention during automatic tasks (e.g. standing and walking) because of their reduced ability to perform dual-tasks ${ }^{3}$. 
Simultaneous tasks (e.g. talking while walking) are performed daily. Dual-task is the

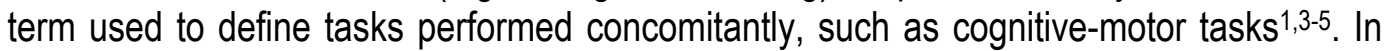
automatic tasks, such as standing, older people with decreased postural control present greater postural oscillation while performing a cognitive task simultaneously, with impairment of balance ${ }^{1,3,4,6}$. This indicates that the cognitive task interferes in the motor control1,3,4,6. According to the complexity of cognitive demand the motor control could be impaired.

Physical exercise is recommended to preserve physical abilities (such as strength and balance) and aerobic resistance, as well as to reduce cognitive decline ${ }^{1,6}$. According to Choi et al. ${ }^{4}$ and Delbroek, et al. ${ }^{1}$, older adults with balance disorders and cognitive deficits show a higher risk of falls, with subsequent diminished physical activity and greater functional dependence. Thus, since ADLs require the management of simultaneous motorcognitive tasks ${ }^{5}$, the exercise program for older adults should provide physical and mental stimulus, with simultaneous demands to confront the reality of the dual-tasks performed on a daily basis.

The American College of Sports Medicine (ACSM) recommends aerobic, strength, endurance, balance, and stretching exercises for older adults to maintain their physical capabilities. The exercise choice depends on the goal of the intervention. However, it is still unclear whether the exercise choice influences postural control variability during a motorcognitive task. The aim of this study was to analyze the effect of individualized exercise (exergame, aerobic, and strength training) on standing balance control during a motorcognitive task in healthy older women. Our hypothesis was that exercise would improve postural balance control during a motor-cognitive task in older women.

\section{METHODS}

A case reports study following the Consensus-based Clinical Case Reporting Guideline Development (CARE) ${ }^{7}$.

\section{Participants}

Sixteen healthy women older adults from Montes Claros city, Minas Gerais State, Brazil were recruited through posters displayed near the university and clinics to participate in a longitudinal research project called "Physical exercise, physical and mental health of older adults". As the adherence of women to this project was greater than men, to maintain homogeneity of the sample, the data of males $(n=4)$ were not included. The inclusion criteria were i) women aged $\geq 60$ years of age, ii) preserved communication ability, iii) independent ambulation, and iv) medical certificate to perform exercise. Participants were excluded if they presented i) musculoskeletal injury that would make it impossible to practice exercise, ii) labyrinthitis or other vestibular disorders, iii) use of psychotropic drugs, iv) cognitive impairment. We used the MMSE to quantify cognitive decline according to educational level, adopting the cutoff scores of 13 points for illiterate participants, 18 for low-middle school (up to 8 years), and 26 for highly schooled individuals (over 8 years) ${ }^{8,9}$. The final score is the sum of the points obtained in each category, totaling 30 points. Data were collected through a history taken with the older women. All participants were informed about the procedures, requirements, risks, and benefits of participation before signing a consent form, which was approved by University's local ethics committee ( $\left.n^{\circ} 1.365 .041 / 2015\right)$. 


\section{Computerized Posturography and dual-task assessment}

The Wii Balance Board (Nintendo®, Kyoto, Japan) platform, with a sampling frequency of $40 \mathrm{~Hz}$, was used to assess balance from the anteroposterior ( $\mathrm{CoP}$ ap) and mediolateral $(\mathrm{CoP} \mathrm{ml}) \mathrm{CoP}$ displacement ${ }^{10}$ for one minute (30 seconds of adaptation to posture and 30 seconds of signal collection) in a standing position.

A routine program using LabVIEW ${ }^{\circledR}$ software, version 8.5 (National Instruments, Texas, USA) was designed for data acquisition and reading on a computer. Data obtained were analyzed through specific routines programmed in Matlab ${ }^{\circledR}$ (MathWorks Inc., USA), which was also used for all statistical procedures. A Fourier transform spectral analysis was performed and all data were filtered using a $3^{\text {rd }}$ order Butterworth low-pass filter with a cutoff frequency of $12 \mathrm{~Hz}$.

The older people stood comfortably on the WBB with their arms at their sides and feet spread shoulder width apart. Postural balance was analyzed in different tasks performed sequentially. The individual remained standing with eyes open (EO) and closed (EC), characterizing a simple motor task. Each test was repeated twice. Subsequently, participants remained in a standing position with eyes open, simultaneously performing a cognitive task (subtraction of seven from one hundred, continuously) ${ }^{11,12}$. This setting characterized the dual-task (DT) paradigm with motor-cognitive demand.

\section{Training Program}

After the balance evaluation, the older women performed different training programs: composed of treadmill aerobic exercise, with intensity maintained between 40 $59 \%$ of heart rate reserve (HRR), which is equivalent to a moderate effort ${ }^{13}$; strength

exercises (exercises of upper and lower limbs, prioritizing large muscle groups and requiring support of body weight), and exergames (exercises with virtual reality). The strength program consisted of squatting exercises on an unstable surface (with shoulder extension and elbow flexion in the anteroposterior axis), frontal pulls on the pulley, and shoulders adduction on the pulley with elbows extended. For exergames, the Nintendo Wii console (Nintendo ${ }^{\circledR}$, Kyoto, Japan) and Wii Balance Board platform (WBB) (Nintendo ${ }^{\circledR}$, Kyoto, Japan) were used. The device packages used were: Wii Fit Plus (Rowing Squat, In Line Lunge, Table Tilt) and Wii Sports Resort (Sword Play Duel, Sword Play Showdown), which consists of exercises for the upper and lower limbs similar to the strength exercise group. All packages were from Nintendo ${ }^{\circledR}$ (Kyoto, Japan).

For all exercises that made up training program, the intensity was monitored with a subjective perceived exertion (SPE) between 05-06 points (moderate intensity), from 0 to 10 points according to the American College of Sports ${ }^{13}$. The training program lasted 3 months, with sessions twice a week, and a session duration of 30 to 45 minutes ${ }^{14}$.

Balance performance was reassessed immediately after the intervention period.

\section{Data Analysis}

Displacement of the center of pressure data in $\mathrm{CoP}_{\text {ap }}$ and $\mathrm{CoP}_{\mathrm{m} /}$ directions, at pretraining and post-training in the DT, EO, and EC conditions was analyzed.

\section{Statistical Analysis}




\section{Research Article}

Data normality was tested using the Lilliefors test. As non-normal distribution was observed, non-parametric tests were performed. The Wilcoxon test was used to compare pre and post-training values of $\mathrm{CoP} m$ and $\mathrm{CoP}_{\text {ap }}$ in the DT, EO, and EC conditions. The effect of dual-task on standing is described in percentage of dual-task interference, calculated according to Rochester et al. ${ }^{15}$. All variables were analyzed at a significance level of $p<0.05$.

\section{RESULTS}

The present study initially proposed different exercise programs, exergames $(n=6)$, strength $(n=5)$, and aerobic $(n=6)$. However, when we analyzed the effect of dual-task on CoP, similar behavior was observed between the different exercise programs, so we decided to analyze the results as a single group.

The evaluated participants were $66 \pm 7$ years, with the following physical characteristics: body mass $62 \pm 9.57 \mathrm{Kg}$, height $1.55 \pm 0.05 \mathrm{~m}$, and body mass index 25.81 $\pm 2,35 \mathrm{Kg} / \mathrm{m}^{2}$.

The $\mathrm{CoP}_{a p}$ and $\mathrm{CoP} \mathrm{ml}_{\mathrm{c}}$ curves in the DT, EO, and EC conditions are shown in figures 1 and 2, respectively. Figure 1 presents the reduced $\mathrm{CoP}_{m /}$ variability in the $\mathrm{EO}$ (standard deviation: pre $=0.05 ;$ post $=0.04$ ), EC (standard deviation: pre $=0.06 ;$ post $=0.05$ ), and DT conditions (standard deviation: pre $=0.12$, post $=0.05$ ). Figure 2 shows that $\mathrm{COP}$ ap variability reduced in EO (standard deviation: pre $=0.23$; post $=0.19$ ) and DT conditions (standard deviation: pre $=0.27$, post $=0.22$ ). Greater variability of the center of pressure displacement was observed in the pre-training condition compared to the post-training moment, except in the $\mathrm{CoP}$ ap in the EC condition, where post training values were higher than pre-training (standard deviation: pre $=0.21$; post $=0.23$ ). In the DT condition there was lower post-training variability compared to pre-training, especially after the first 05 seconds (which represents the instant of time when the examiner says the numbers to calculate). 


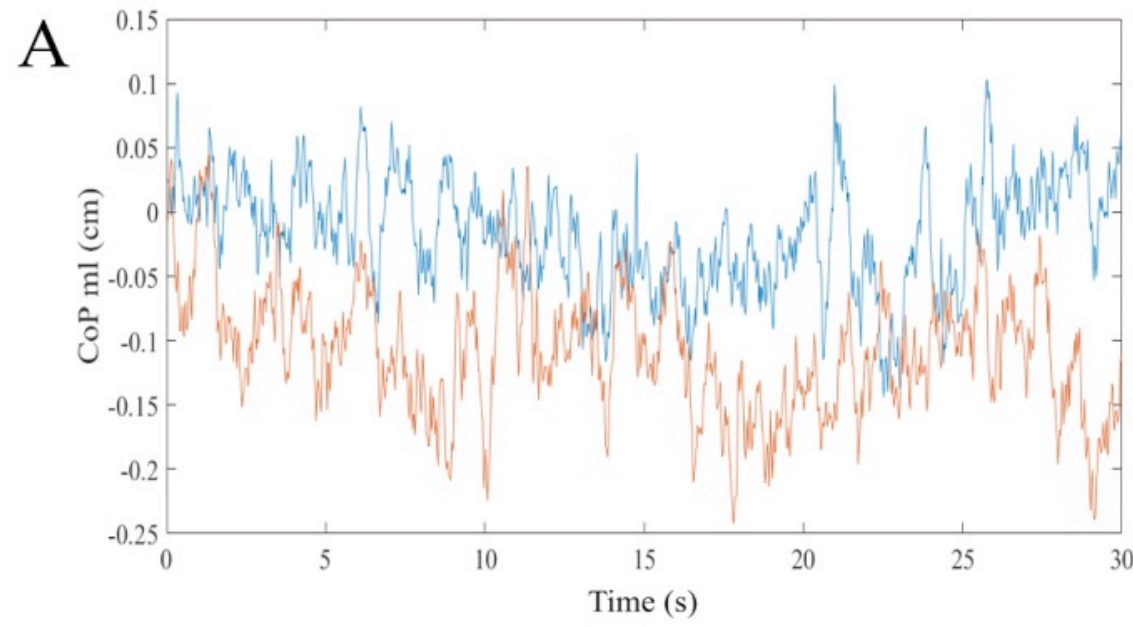

$\mathrm{Z}$ score $=28.97$ p-value $<0.01$

B

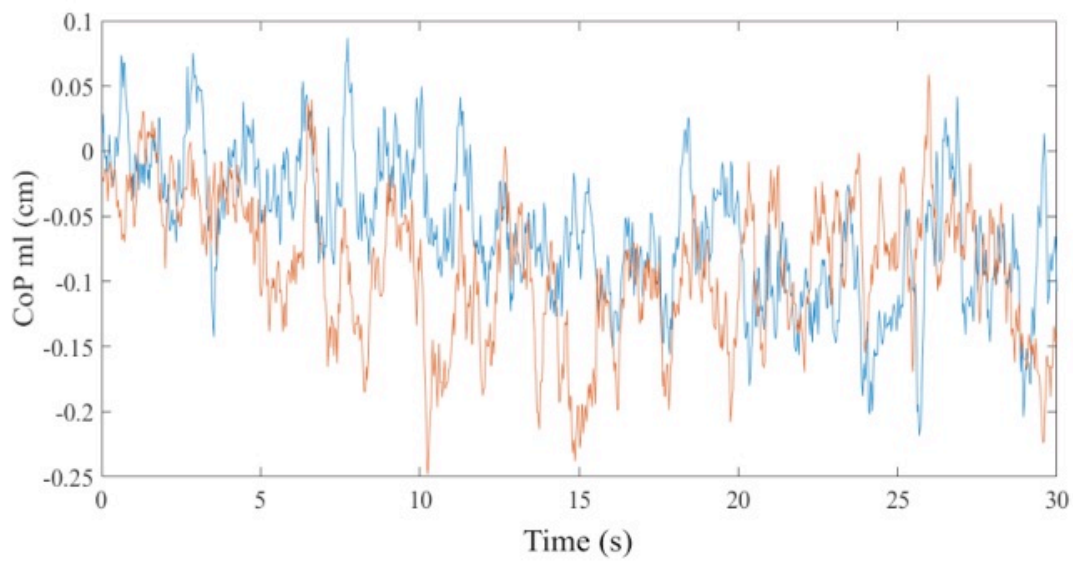

$\mathrm{Z}$ score $=26.70$ p-value $<0.01$

Time (s)
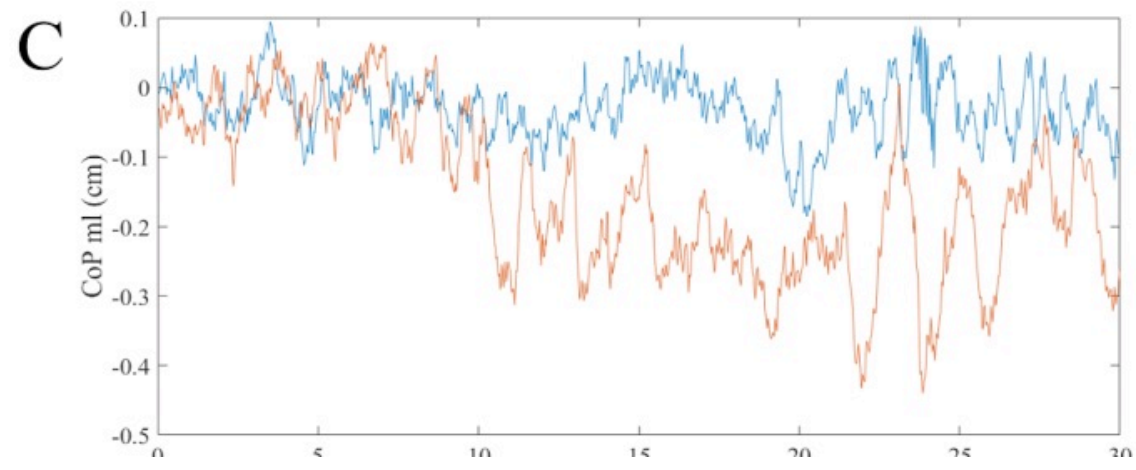

$\mathrm{Z}$ score $=14.33$

p-value $<0.01$

Figure 1. Median curves of variability (standard deviation, $S D$ ) of the center of pressure displacement in the mediolateral direction (CoP $\mathrm{ml}$ ) of 16 older women. A) eyes open, B) eyes closed, and C) dual-task. The red and blue curves represent the CoP variability over time (pre- and post-training data, respectively). 

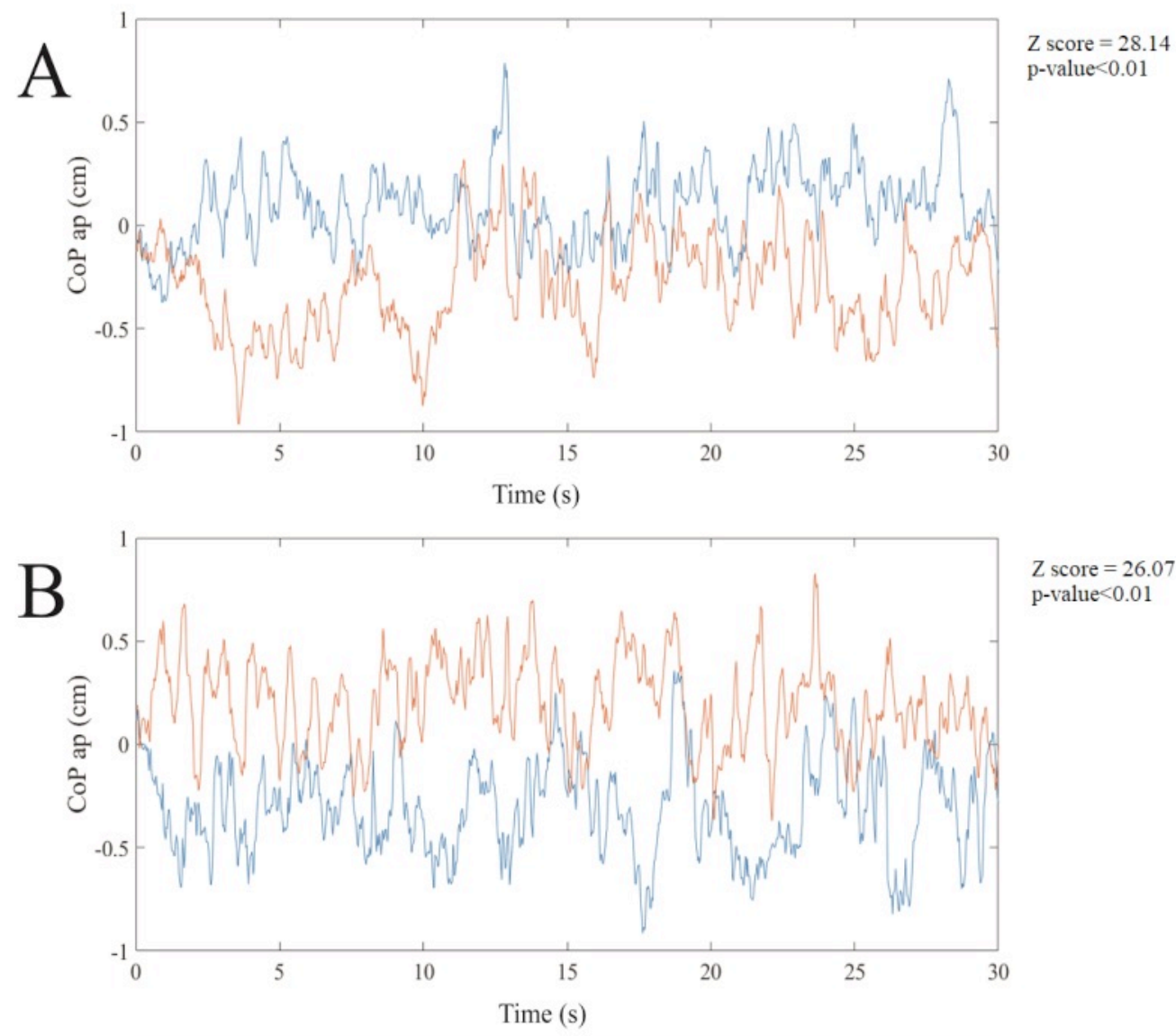

$\mathrm{Z}$ score $=26.07$ p-value $<0.01$

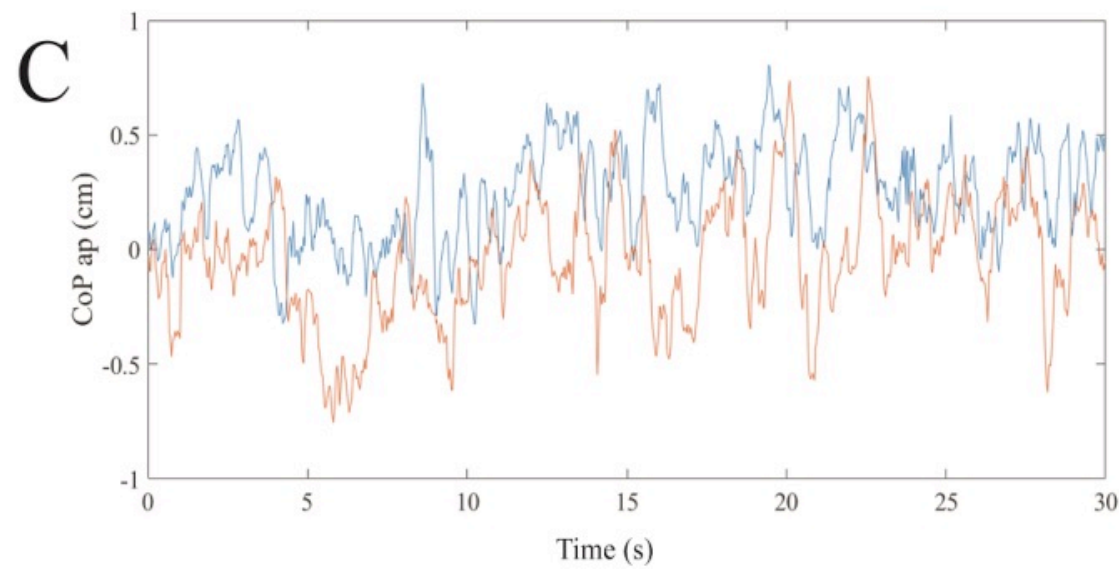

$Z$ score $=29.35$ p-value $<0.01$

Figure 2. Median curves of variability (standard deviation, SD) of the center of pressure displacement in the anteroposterior direction (CoP ap) of 16 older women. A) eyes open, B) eyes closed, and C) dual-task. The red and blue curves represent the CoP variability over time (pre- and post-training data, respectively).

Table 1 presents the median values of $\mathrm{CoP}_{\text {ap }}$ and $\mathrm{CoP}_{m /}$ variability in the different tasks, where significant differences can be observed between the pre- and post-training period. $\mathrm{CoP}_{m /}$ decreased post-training in all conditions evaluated, whereas $\mathrm{CoP}_{\text {ap }}$ increased in DT and EC, and decreased only in EO. 
Brazilian Journal of Motor Behavior

\section{Research Article}

Table 1 - Median of variability of displacement of the pressure center in the anteroposterior (CoP ap) and mediolateral (CoP $m /)$ under different pre and post-training conditions from the Wilcoxon analysis.

\begin{tabular}{|c|c|c|c|c|c|c|}
\hline & \multicolumn{3}{|c|}{ CoP ap } & \multicolumn{3}{|c|}{ CoP ml } \\
\hline & Pre & Post & p-value & Pre & Post & p-value \\
\hline DT & 0.04 & 0.26 & $p<0.01$ & 0.16 & 0.03 & $p<0.01$ \\
\hline EO & 0.29 & 0.09 & $p<0.01$ & 0.11 & 0.02 & $p<0.01$ \\
\hline EC & 0.20 & 0.31 & $p<0.01$ & 0.09 & 0.06 & $\mathrm{p}<0.01$ \\
\hline
\end{tabular}

The lower variability in mediolateral displacement when the participants were exposed to a dual-task condition was the most important finding of this study. Posture control in the vertical position occurs from ankle ( $\mathrm{CoP}$ ap) and hip ( $\mathrm{CoP}$ ml) range of motion ${ }^{16}$. Rodrigues et al. ${ }^{17}$ observed that in older adults, cognitive load during dual-task impairs balance, mainly in the mediolateral direction, with an increase in CoP oscillation in the mediolateral direction.

Studies describe ${ }^{18,19}$ that permanent balance ability in older adults may be related to the regular pattern of $\mathrm{CoP}$ variability. Yamagata et al. ${ }^{19}$ suggest that maintaining stability in the frontal plane is relatively easier due to the larger support base during the position. While healthy young adults control postural balance in the sagittal plane during $\mathrm{DT}^{20}$, older adults maintain postural control in the frontal plane during the DT condition. In the present study, before the training, the participants demonstrated greater mediolateral oscillation $\left(\mathrm{CoP} \mathrm{ml}^{\prime}\right)$ and lower anteroposterior oscillation ( $\left.\mathrm{CoP}{ }_{a p}\right)$, indicating the use of the hip as a main strategy for balance control. However, after physical training, the participants presented lower variability in $\mathrm{CoP} m$ and greater variability in $\mathrm{CoP}_{a p}$ during EO and DT. These findings show that physical training could promote changes in the postural control strategy, with greater use of the ankle to the detriment of hip utilization. This demonstrates that the participants who performed 24 sessions of differentiated exercises presented similar control of body stability to that observed in young adults.

A physical exercise program with dual-task training seems to have effects on the balance of older adults. Li et al. ${ }^{6}$, evaluated single-support standing balance with eyes open and closed, which involved standing on the dominant leg for $10 \mathrm{~s} /$ trial. The authors found significant effects of decreased CoP variability post-training. The results are similar to the findings in our study, although we assessed double-support standing balance. In a systematic review, Wollesen \& Voelcker-Rehage ${ }^{3}$ investigated the benefit of dual-task training for healthy older adults with regard to the training program and task conditions. The authors found that exercises in dual-task improved standing balance in dual-task conditions and this could be achieved with specific and general exercises.

The change in strategy promoted by training in postural balance control is important in relation to the incidence of falls and fractures in older adults, as it reveals improvement in motor performance due to postural adjustments ${ }^{1,4}$. Another important aspect regarding falls 
Brazilian Journal of Motor Behavior

is the impairment in neural processing of older adults, which decreases executive function and attentional resources ${ }^{1,2}$.

Decreased variability of $\mathrm{CoP}_{\mathrm{m} /}$ may be related to improvement in neural processing promoted by the varied exercise program in dual-task. Performance in the secondary task (cognitive task) was not recorded, since speech can interfere in the assessment of balance, so only a mental calculation task was given. In pre-training, the older women presented greater variability in center of pressure displacement in the dual-task condition, possibly because they required more attention and motor planning to maintain balance. At posttraining, lower variability was observed in the dual-task condition, suggesting lower neural competition between cognitive or motor tasks with the exercise program. The post-training dual-task cost did not differ from pre-training, however, an improvement was observed in the motor strategy for balance control of participants, which represents a lesser shift of attention to the cognitive task.

This relationship between cognition and balance is important for the development of evaluation and treatment strategies related to aging 1,4 . We speculate that due to the effects of exercise on the brain ${ }^{21}$, the reduction in mediolateral variability could be related to greater motor synchrony managed by the bilateral motor cortices, which would result in better bilateral side-by-side postural control. However, as this was not investigated in the present study, this is only a hypothetical suggestion.

According to the present study it is suggested that physical exercise (24 sessions of 30-45 min) performed twice a week can improve dual-task cognitive processing. However, some limitations of this study should be highlighted: 1) the small sample size; 2) absence of a control group or different exercise groups.

\section{CONCLUSION}

Physical exercise programs for older women may simultaneously contribute to improving both motor and cognitive performance. The reduction in mediolateral displacement ( $\left.\mathrm{CoP}_{\mathrm{ml}}\right)$ variability in postural control and potential improvement in the divided attention may positively influence improvement in motor and cognitive performances.

\section{REFERENCES}

1. Delbroek T, Vermeylen W, Spildooren J. The effect of cognitive-motor dual task training with the biorescue force platform on cognition, balance and dual task performance in institutionalized older adults: a randomized controlled trial. J PhysTher Sci.

2017;29(7):1137-1143.

2. Heffernan KS, Augustine JA, Lefferts WK, et al. Arterial stiffness and cerebral hemodynamic pulsatility during cognitive engagement in younger and older adults. ExpGerontol. 2018;101:54-62.

3. Wollesen B, Voelcker-Rehage C. Training effects on motor-cognitive dual-task performance in older adults. European Review of Aging and Physical Activity. 2014;11:524. 


\section{Research Article}

4. Choi JH, Kim BR, Han EY, Kim SM. The effect of dual-task training on balance and cognition in patients with subacute post-stroke. Ann Rehabil Med. 2015;39(1):81-90.

5. Woollacott M, Shumway-Cook A. Attention and the control of posture and gait: a review of an emerging area of research. Gait \& Posture. 2002;16(1):1-14.

6. Li KZ, Roudaia E, Lussier M, Bherer L, Leroux A, McKinley PA. Benefits of cognitive dualtask training on balance performance in healthy older adults. J Gerontol A BiolSciMedSci. 2010;65(12):1344-1352.

7. Gagnier J, Kienle G, Altman D, et al. The CARE guidelines: consensus-based clinical case reporting guideline development. BMJ CASE REPORTS. 2013.

8. Bertolucci PH, Brucki SM, Campacci SR, Juliano Y. [The Mini-Mental State Examination in a general population: impact of educational status]. ArqNeuropsiquiatr. 1994;52(1):1-7.

9. Folstein MF, Folstein SE, McHugh PR. "Mini-mental state". A practical method for grading the cognitive state of patients for the clinician. J Psychiatr Res. 1975;12(3):189-198.

10. Monteiro-Junior RS, Ferreira AS, Puell VN, et al. Wii Balance Board: Reliability and Clinical Use in Assessment of Balance in Healthy Elderly Women. CNS \& Neurological Disorders Drug Targets. 2015;14(9):1165-1170.

11. Theill N, Martin M, Schumacher V, Bridenbaugh SA, Kressig RW. Simultaneously measuring gait and cognitive performance in cognitively healthy and cognitively impaired older adults: the Basel motor-cognition dual-task paradigm. Journalofthe American GeriatricsSociety. 2011;59(6):1012-1018.

12. Wrightson JG, Smeeton NJ. Walking modality, but not task difficulty, influences the control of dual-task walking. Gait\&Posture. 2017;58:136-138.

13. Thompson PD, Arena R, Riebe D, Pescatello LS. ACSM's new preparticipation health screening recommendations from ACSM's guidelines for exercise testing and prescription, ninth edition. Curr Sports Med Rep. 2013;12(4):215-217.

14. Chodzko-Zajko WJ, Proctor DN, Fiatarone Singh MA, et al. American College of Sports Medicine position stand. Exercise and physical activity for older adults. Med Sci Sports Exerc. 2009;41(7):1510-1530.

15. Rochester L, Galna B, Lord S, Burn D. The nature of dual-task interference during gait in incident Parkinson's disease. Neuroscience. 2014;265:83-94.

16. Lakhani B, Mansfield A. Visual feedback of the centre of gravity to optimize standing balance. Gait \& Posture. 2015;41(2):499-503.

17. Rodrigues ACMA, Tinini RCR, Gatica-Rojas V, et al. Motor-cognitive dual-task performance of older women evaluated using Wii Balance Board. Aging ClinExp Res. 2019.

18. Ramdani S, Seigle B, Lagarde J, Bouchara F, Bernard PL. On the use of sample entropy to analyze human postural sway data. Medical Engineering\&Physics. 2009;31(8):10231031. 
Brazilian Journal of Motor Behavior

\section{Research Article}

19. Yamagata M, Ikezoe T, Kamiya M, Masaki M, Ichihashi N. Correlation between movement complexity during static standing and balance function in institutionalized older adults. Clinical Interventions in Aging. 2017;12:499-503.

20. Donker SF, Roerdink M, Greven AJ, Beek PJ. Regularity of center-of-pressure trajectories depends on the amount of attention invested in postural control. Experimental BrainResearch. 2007;181(1):1-11.

21. Portugal EMM, Cevada T, Monteiro-Junior RS, et al. Neuroscience of exercise: from neurobiology mechanisms to mental health. Neuropsychobiology. 2013;68(1):1-14.

\section{ACKNOWLEDGEMENTS}

We thank the following funding agencies: Coordenação de Aperfeiçoamento de Pessoal de Nível Superior (Capes), Conselho Nacional de Desenvolvimento Científico e Tecnológico (CNPq) and Fundação de Amparo à Pesquisa do Estado de Minas Gerais (FAPEMIG).

Citation: Rodrigues ACMA, Tinini RCR, Gatica-Rojas V, De Paula AMB, Guimarães ALS, Monteiro-Junior

RS.Influence of exercise on cognitive processing of older woman during dual-task balance: sixteen case reports.

BJMB. 2020: 14(1): 14-23.

Editors: Dr Fabio Augusto Barbieri - São Paulo State University (UNESP), Bauru, SP, Brazil; Dr José Angelo Barela São Paulo State University (UNESP), Rio Claro, SP, Brazil; Dr Natalia Madalena Rinaldi - Federal University of Espírito Santo (UFES), Vitória, ES, Brazil.

Copyright:@ 2020 Rodrigues, Tinini, Gatica-Rojas, De Paula, Guimarães and Monteiro-Junior and BJMB. This is an open-access article distributed under the terms of the Creative Commons Attribution-NonCommercial-NoDerivatives 4.0 International License which permits unrestricted use, distribution, and reproduction in any medium, provided the original author and source are credited.

Funding: This study was supported by Coordenação de Aperfeiçoamento de Pessoal de Nível Superior (Capes), Conselho Nacional de Desenvolvimento Científico e Tecnológico (CNPq) and Fundação de Amparo à Pesquisa do Estado de Minas Gerais (FAPEMIG).

Competing interests: The authors have declared that no competing interests exist.

DOI: https://doi.org/10.20338/bjmb.v14i01.160 